Agenda Internacional

Año XXV No 36, 2018, pp. 25-43

ISSN $1027-6750$

\title{
El intento secesionista en Cataluña a la luz del Derecho internacional
}

\author{
Ana Gemma López Martín* \\ José Antonio Perea Unceta**
}

\section{RESUMEN}

El intento de secesión promovido en 2017 por una parte de los miembros del Parlamento de Cataluña plantea cuestiones de enorme interés para el Derecho internacional. En primer lugar, respecto de si las minorías nacionales, grupos o pueblos tienen reconocido en el ordenamiento internacional un derecho de libre determinación como el que disfrutan los pueblos sometidos a dominación colonial o por la fuerza; si se ha consolidado como costumbre internacional el denominado derecho a la 'secesión-remedio' y si puede haber otros fundamentos para la secesión de esta clase de pueblos, como el principio democrático o teoría de la mayoría. Y, en segundo lugar, en relación con la necesaria efectividad de una declaración de independencia y la constatación de los elementos que conforman un Estado y permiten confirmar su creación; con el cumplimiento, en ese proceso de creación, de la legalidad internacional, y con la consecuente obligación, en caso contrario, de no reconocimiento de esas entidades surgidas de la violación del Derecho internacional.

Palabras clave: secesión, Cataluña, creación de Estados, reconocimiento.

\section{The secessionist attempt in Catalonia in the light of International Law}

\section{Abstract}

The attempted secession promoted in 2017 by a part of the members of the Parliament of Catalonia raises questions of enormous interest for International Law. In the first place, regarding whether national minorities, groups or peoples have recognized in the international

\footnotetext{
* Doctora en Derecho. Catedrática ac. de Derecho Internacional Público de la Facultad de Derecho de la Universidad Complutense de Madrid (España). Dirección electrónica: anagema@ucm.es

** Doctor en Derecho. Profesor contratado. Doctor de Derecho Internacional Público de la Facultad de Derecho de la Universidad Complutense de Madrid (España). Dirección electrónica: japereau@ucm.es
} 
order a right of self-determination such as that enjoyed by peoples subject to colonial domination or by force; if the so-called right to secession-remedy has been consolidated as an international custom and if there can be other foundations for the secession of this kind of peoples, such as the democratic principle or majority theory. And second, in relation to the effectiveness of a declaration of independence and the verification of the elements that make up a State and allow confirming its creation; with compliance, in that process of creation, of international legality, and the consequent obligation, otherwise, of non-recognition of those entities arising from the violation of International Law.

Keywords: Secession, Catalonia, Creation of States, Recognition.

\section{Introducción}

En los últimos años, Cataluña se ha convertido en el centro de atención a nivel internacional de los fenómenos independentistas, superando a otros anteriores - como Quebec - y coetáneos, como Escocia, Crimea o Kurdistán. En el primer caso, hubo una ley habilitante de las cámaras del Parlamento de Canadá (Clarity Act, de 2000) y en el segundo, el Parlamento y el Gobierno británicos, de forma consensuada con el Gobierno autónomo escocés (Acuerdo de Edimburgo de 15 de octubre de 2012), culminaron el proceso con un referéndum fallido de independencia en 2014, lo que los sitúa en la institución de la 'separación' de parte del territorio de un Estado, que se distingue de la 'secesión' en que en esta no hay consentimiento del Estado 'matriz' (parent State). Completamente diferente es, en esta línea, el caso de Crimea, pues el referéndum de 16 de marzo de 2014 no fue autorizado por la Rada Suprema de Ucrania y, por tanto, la posterior declaración de independencia del Consejo Supremo de Crimea y de la ciudad de Sebastopol y la integración de ambos territorios en la Federación de Rusia vulneran el principio de integridad territorial de los Estados, como se declaró, entre otras, en la Resolución 68/262, de 27 de marzo de 2014, de la Asamblea General de la ONU¹.

En el mismo contexto que el caso ucraniano se sitúa el proceso secesionista iniciado en Cataluña por una parte de sus partidos políticos con el referéndum de 9 de noviembre de 2014 y que ha protagonizado la atención internacional desde que se aprobaran en su Parlamento la Ley 19/2017, de 6 de septiembre, del Referéndum de Autodeterminación de Cataluña y la Ley 20/2017, de 8 de septiembre, de Transitoriedad Jurídica y Fundacional de la República Catalana, se celebrara el

\footnotetext{
1 Obsérvese, no obstante, que fue adoptada con 100 votos favorables, 11 en contra, 58 abstenciones y 24 ausencias, evidenciando la enorme politización de este tipo de fenómenos.
} 
1 de octubre un referéndum sin autorización del Estado - y pese a las decisiones al respecto del Tribunal Constitucional—y de que, finalmente, el 10 y el 27 de octubre de 2017 se aprobase en el Parlamento de la Comunidad Autónoma de Cataluña su Declaración Unilateral de Independencia. Todos estos actos han sido promovidos por una mayoría de los parlamentarios catalanes (entre 70 y 72 de los 135 integrantes del parlamento autonómico), con el respaldo de algo menos de la mitad del electorado de la comunidad autónoma ${ }^{2}$ y vulnerando el ordenamiento jurídico nacional, tanto la Constitución española de 1978 como el Estatuto de Autonomía de Cataluña de 1979, reformado en 20063. Por ello, tanto los tribunales nacionales, como el Senado han actuado para, respectivamente, anular esas actuaciones legislativas, así como procesar penalmente a sus responsables y para sustituir temporal y provisionalmente al Gobierno autonómico por el del Estado, conforme a las previsiones constitucionales.

Esta actuación y la pretensión, aun persistente, de los independentistas catalanes, plantean cuestiones de indudable interés desde la perspectiva del Derecho internacional. No solo porque lo que se ha pretendido, sin éxito hasta ahora, es la creación de un nuevo Estado y su reconocimiento por la comunidad internacional, sino también porque sus promotores se han amparado para fundamentar su intento de secesión de forma absolutamente cuestionable en el derecho de libre determinación de los pueblos y en otros principios más imprecisos supuestamente recogidos en el ordenamiento jurídico internacional. Estas cuestiones se analizan en este estudio, en el orden cronológico y secuencial de las actuaciones realizadas, esto es, comenzando por las leyes de referéndum y de «desconexión» — como fue denominada por sus promotores- y terminando por la declaración de independencia.

\section{La pretendida fundamentación de los actos secesionistas del Parlamento de Cataluńa en el Derecho internacional de la libre determinación de los pueblos}

Cuando en septiembre de 2017 los partidos independentistas aprueban en el Parlamento de Cataluña la Ley de Referéndum se atribuyen la titularidad para autodeterminarse $^{4}$ - por cierto, sorteando los mecanismos de garantía de la legalidad e incluso las mayorías establecidos en sus propias normas reglamentarias y

\footnotetext{
2 En las elecciones al parlamento catalán de 2015 los partidos favorables a la independencia obtuvieron el 47,74\% de los votos válidos emitidos, 1958348 de los 4115807 contabilizados.

3 Como se ha resuelto, entre otras, en las Sentencias del Tribunal Constitucional de 17 de octubre y de 8 de noviembre de 2017.

4 En su artículo 1 se dice que el pueblo de Cataluńa es un sujeto político soberano y como tal ejerce el derecho a decidir libre y democráticamente su propia condición política.
} 
estatutarias - fundamentando dicha consideración en el ordenamiento jurídico internacional. Para ello utilizaron tres argumentos: el derecho de libre determinación de los pueblos, el derecho a la secesión-remedio y el principio democrático.

\subsection{Inexistencia actual de un derecho de libre determinación de los pueblos no sometidos a dominación colonial}

En la referida Ley de Referéndum se expone tanto en su preámbulo (párrafo quinto) como en su articulado (artículo 3.3) que dicha norma está amparada en el derecho de autodeterminación de los pueblos consagrado en el ordenamiento jurídico internacional. A este respecto hay que señalar que en el Derecho internacional vigente no existe ninguna norma que permita tal afirmación en el supuesto concreto de Cataluña.

En el Derecho internacional se distinguen, principalmente, tres clases de pueblos: los sometidos a dominación colonial, las minorías nacionales y las poblaciones indígenas. Los pueblos coloniales están caracterizados por ser diferentes de la población de la metrópoli, tener diferentes derechos (especialmente políticos), estar sometidos al dominio de aquella y estar asentados en un territorio separado geográfica y jurídicamente de esa potencia dominante ('criterio del agua salada') ${ }^{5}$. A estos pueblos se les reconoce, desde la Resolución 1514 (XV), de 14 de diciembre de 1960, de la Asamblea General de la ONU, el derecho a su libre determinación en su vertiente externa, esto es, con un pleno derecho a decidir su estatuto político. Conforme al régimen establecido por las Naciones Unidas, han de pronunciarse en un referéndum con todas las garantías democráticas si quieren convertirse en un Estado independiente o libremente asociado con su metrópoli o si desean integrarse en esta sin ninguna condición específica o en una relación federal, confederal, etc. La Resolución de la Asamblea General de 1960 y, posteriormente, la 2625 (XXV), de 24 de octubre de 1970, cristalizaron y consolidaron, respectivamente, una norma consuetudinaria internacional, como consecuencia de la práctica internacional, con naturaleza de ius cogens según ha confirmado la Corte Internacional de Justicia $(\mathrm{CIJ})^{6}$. Y por previsión expresa de este régimen jurídico se extiende, igualmente, a los pueblos sometidos por el uso de la fuerza. Resulta evidente que, en este caso, no estamos ante un pueblo sometido a dominación colonial, puesto que su territorio no está separado geográficamente, no disfrutan de derechos políticos inferiores y no se encuentran en ninguna

\footnotetext{
Véase la Resolución 1541 (XV), de 15 de diciembre de 1960, de la Asamblea General de la ONU.

6 Entre otras, en las opiniones consultivas sobre las Consecuencias jurídicas para los Estados de la presencia continuada de Sudáfrica en Namibia (Sudoeste africano), no obstante la Resolución 276 (1970) del Consejo de Seguridad, de 21 de junio de 1970, y sobre el Sáhara occidental, de 16 de octubre de 1975, y en la Sentencia sobre Timor oriental (Portugal c. Australia), de 30 de junio de 1995.
} 
situación de subordinación. Como tampoco es cierto, como se afirma en la exposición de motivos de la Ley de Referéndum, que se haya sustraído «la tradició jurídica i institucional del poble català nomès interrompuda a llarg dels segles per la força de les armes» (párrafo quinto in fine, cursiva añadida).

En términos objetivos sí puede hablarse de un pueblo catalán como minoría nacional, en los términos en que se ha definido por la Asamblea Parlamentaria del Consejo de Europa, que es su contexto jurídico, puesto que sus integrantes tienen diferencias culturales (especial pero no solamente lingüísticas), son residentes y nacionales del Estado en el que se integran, mantienen lazos duraderos con el resto de España desde hace mucho tiempo (durante la Hispania romana y visigoda, hasta el siglo VIII, e ininterrumpidamente desde el siglo XII), están implantados en un territorio identificable en el que son suficientemente representativos, sin ser mayoritarios respecto de la población del Estado, y tienen una voluntad de preservar su identidad común 7 . En términos subjetivos es, obviamente, opinable si ha expresado mayoritariamente su voluntad de constituirse en una entidad política diferente del Estado espańol, que es un requisito imprescindible para una eventual autodeterminación externa, pero no para su consideración en otros ámbitos, como el reconocimiento de su diferenciación y su no discriminación, en el contexto de la protección de sus derechos fundamentales.

Sin embargo, hay que tener en cuenta que ni los Pactos de Nueva York de 1966 sobre Derechos Civiles y Políticos y sobre Derechos Económicos Sociales y Culturales — citados en el primer párrafo de la exposición de motivos de la Ley de Referéndum-, ni ningún otro tratado internacional extienden el derecho de libre determinación de los pueblos — plenamente reconocido solo a los pueblos sometidos a dominación colonial o por la fuerza - a otro tipo de pueblos, y, por tanto, ni a las minorías nacionales ni a las poblaciones indígenas. Como ha sido explicado con todo rigor por la doctrina, incluyendo a quienes participaron directamente en la redacción de los Pactos, cuando se redactó su artículo 1 común se pensó exclusivamente en la autodeterminación interna de todos los pueblos (derecho de las poblaciones de los Estados a estar dotados de un gobierno que represente sin distinción alguna a la totalidad del pueblo) y en la externa (independencia, entre otras opciones) solo de los pueblos coloniales, tal y como se había reconocido en las resoluciones aprobadas en 1960 por la Asamblea General de la ONU (Humphrey, 1984, p. 129; Hannum, 1993, p. 25; Higgins, 1994, p. 111; Cassese, 1995, p. 143; Palmisano, 1997, pp. 107-145; Musgrave, 2000, p. 92).

Véase la Recomendación 1201, de la Asamblea Parlamentaria del Consejo de Europa, de 1 de febrero de 1993. 
En coherencia con esta consideración, las declaraciones y los convenios internacionales, del ámbito universal y de los diferentes ámbitos regionales no han reconocido la libre determinación fuera del ámbito colonial, restringiendo el régimen jurídico internacional de las minorías nacionales a la protección de sus derechos humanos. Así ha sido en textos —unos no vinculantes y otros sí- como la Declaración de 1992 de las Naciones Unidas sobre los derechos de las personas pertenecientes a minorías nacionales, étnicas, religiosas o lingüísticas, el Acta Final de Helsinki de 1975 (CSCE), la Carta de París para una Nueva Europa de 1990 (CSCE), las Recomendaciones Lund de 1999 (OSCE) y la Carta Europea de las Lenguas Regionales o Minoritarias de 1992 (Consejo de Europa).

\subsection{La problemática vigencia de la doctrina de la secesión-remedio}

Cuando se completó en la Resolución 2625 (XXV) de 1970 el régimen relativo a la descolonización - con el objetivo de no dejar ningún resquicio a las pretensiones de supervivencia del dominio ultramarino portugués, especialmente- también se incluyó un último párrafo en ese apartado sobre la libre determinación de los pueblos referido intencionadamente, como se desprende de los debates, a las situaciones no coloniales. Este párrafo advierte de la vigencia del principio del respeto a la integridad territorial en los supuestos en los que los Estados estén dotados de un gobierno que represente a la totalidad del pueblo perteneciente al territorio, sin distinción por motivos de raza, credo o color. Es lo que se conoce, en sus diferentes interpretaciones doctrinales, como 'cláusula de salvaguardia de la integridad territorial', 'cláusula democrática', 'teoría de la opresión’ o 'doctrina de la secesión-remedio'.

Aunque algunos autores hacen una interpretación estricta de esta cláusula, restringiéndola a los regímenes segregacionistas de la década de 1970 (Hannum, 1993, p. 2), otros, sin embargo, defienden su vigencia, en general, para los supuestos de violación grave, masiva y sistemática de los derechos humanos de las minorías por parte del Estado motivada por el hecho de serlo. Esto es lo que se conoce como 'secesión-remedio', ya que se concibe como la última solución (remedial right view), absolutamente excepcional respecto del principio de integridad territorial de los Estados ${ }^{8}$, y solo en casos muy graves de opresión (oppresion theory).

No obstante, para que una resolución de la Asamblea General — formalmente recomendatoria - pueda considerarse como norma y, por tanto, tenga efectos vinculantes para los Estados, es necesario que vaya acompañada de una práctica uniforme y generalmente aceptada como derecho, tal y como sucedió, y así hemos señalado,

\footnotetext{
8 Entre otros, Buccheit, 1978; Christakis, 1989; Tomuschat, 1998; Tancredi, 2001; Crawford, 2006; Carrillo Salcedo, 2012; Soroeta, 2013; Pons Rafols, 2015; Martínez Jimenez, 2015; Anderson, 2016.
} 
con la Resolución 1514 (XV) en relación con la libre determinación de los pueblos coloniales. Y en nuestra opinión y la de buena parte de la doctrina ${ }^{9}$, la declaración efectuada en 1970 en ese órgano de la ONU no cuenta con una práctica anterior ni posterior que avale su consideración como norma consuetudinaria internacional. Las matanzas de ibos en Biafra (1967-1970), la discriminación legal de los tamiles de Sri Lanka (1983-2009) o las masacres sobre los kurdos de Iraq (1986-1989) no han sido suficientes para que la comunidad internacional respaldara sus intentos de secesión. Y, si bien el incumplimiento por Etiopía de los acuerdos cuasi confederales que garantizaban la convivencia entre grupos étnicos fundamentó el apoyo de Naciones Unidas a la secesión de Eritrea (1993), una vulneración similar no sirvió en el caso los turcochipriotas (1974). Como tampoco ha habido una actuación pareja en los casos de Bangladesh (1971) y la Krajina serbocroata (1991-1995) o entre Bosnia-Herzegovina (1991) y Kosovo (1999), con situaciones evidentes de discriminación legal o incluso, en algunos casos, de limpieza étnica. Los casos de secesión anteriores a 1970 (Panamá, Finlandia o Mongolia) y los posteriores (Bangladesh, Estonia, Letonia, Lituania, Eslovenia, Croacia, Macedonia, Bosnia-Herzegovina, Eritrea y Sudán del Sur) no permiten, en absoluto, prescribir la existencia de una costumbre internacional iniciada con la Resolución 2625 (XXV) de 1970, y basada en la 'secesión-remedio', por mucho que haya una corriente doctrinal progresivamente favorable y que algunos Estados se hayan pronunciado favorablemente ${ }^{10}$.

Como es bien sabido, y como se ha criticado con todo acierto ${ }^{11}$, la CIJ no aprovechó su opinión consultiva sobre la declaración de independencia efectuada por el Parlamento de Kosovo en 2008 para establecer el estado actual de la secesión fuera del ámbito de la descolonización, limitándose a declarar que no están reguladas - y por tanto tampoco prohibidas - esas declaraciones de independencia, de naturaleza interna, como expondremos más adelante. Tampoco, es, en consecuencia, rigurosa la afirmación contenida en el párrafo cuarto de la Ley de Referéndum catalana, ni en lo referido a este dictamen ni en lo relativo a la 'secesión-remedio', como se ha expuesto anteriormente. A este respecto, resulta notorio que, aunque esta doctrina tuviera una plena vigencia, en el supuesto de Cataluña no hay discriminación de su población (como se afirma en el párrafo sexto de esta ley) ni otras violaciones graves de las normas internacionales (como se insinúa en el párrafo cuarto).

\footnotetext{
9 Entre otros, Guilhaudis, 1976; Gros Espiell, 1976; Nanda, 1981; Shaw, 1991; Remiro Brotóns, 2001; Bermejo y Gutiérrez Espada, 2008; Wilson, 2009; Vidmar, 2015.

10 Por ejemplo, en las alegaciones efectuadas en el procedimiento de la opinión consultiva de la CIJ sobre Kosovo (2010) o en el Dictamen del Tribunal Supremo de Canadá de 20 de agosto de 1998 sobre el referéndum de Quebec. 11 Entre otros, los jueces Yusuf, Simma y Sepúlveda-Amor en sus opiniones separadas en la Opinión Consultiva de 22 de julio de 2010 .
} 


\subsection{Las doctrinas políticas que pretenden fundamentar la secesión de territorios}

Es habitual que cuando las circunstancias reales de un pueblo no colonial no permiten recurrir a la 'secesión-remedio', se busque el fundamento de sus pretensiones secesionistas al margen de dicha doctrina y del régimen jurídico realmente vigente de la libre determinación de los pueblos. En estos casos, los argumentos esgrimidos son, generalmente, la reparación de injusticias históricas, la recuperación de la estatalidad perdida o la simple voluntad de la población. Ninguno de ellos está amparado en el ordenamiento jurídico internacional.

Tanto el recurso a la 'legitimidad histórica' (párrafo quinto de la Ley de Referéndum), como a la 'gestión pública democrática' (párrafo tercero) son ajenos al régimen jurídico internacional de libre determinación (externa) de los pueblos y al proceso lícito de creación de Estados. En Derecho internacional no existe un derecho a recuperar la estatalidad perdida al margen de las ocupaciones por uso de la fuerza desde que esta fue prohibida — en general y, por tanto, como medio de adquisición del territorioen la Carta de las Naciones Unidas de 1945. En este sentido, los derechos soberanos de alguna forma preservados a Kuwait cuando fue invadida y anexionada por Iraq en agosto de 1990 hasta su liberación en febrero de 1991 no son aplicables a otros supuestos anteriores a 1945 (Cassese, 1995, p. 263), por mucho que respecto de las repúblicas bálticas se predicara en 1990 por algún autor (Eastwood, 1992, p. 316).

Del mismo modo, la apelación al 'principio democrático', denominado en el contexto independentista catalán 'derecho a decidir', y que implica la equivalencia entre la autodeterminación interna y la externa, y en consecuencia la prevalencia de la expresión de la voluntad mayoritaria del sujeto autodeterminado, sin otras condiciones, tampoco tiene sustento en el vigente ordenamiento jurídico internacional ${ }^{12}$. Esto es así, primeramente, porque no hay una norma que establezca como obligatorio a nivel universal el sistema democrático, ni lo defina y regule pormenorizadamente, ni lo aplique específicamente a los pueblos minoritarios. En el contexto regional europeo, sin embargo, existe la obligación, para los Estados miembros del Consejo de Europa de constituirse en democracias - con el derecho a unas elecciones libre y periódicas - y Estados de Derecho — esto es, con el cumplimiento de la legislación por las administraciones públicas y los ciudadanos, y el sometimiento a los tribunales de justicia de ambos (Jarillo, 2012, p. 430) — que protejan y hagan efectivos los derechos y libertades fundamentales. El error del independentismo catalán es amputar de

\footnotetext{
12 Como señala Pons Rafols (2015, pp. 43-44), «el pretendido derecho a decidir resulta más bien, a mi entender, un artificio semántico, aunque sin duda ha sido un artificio muy exitoso políticamente», pese a que «ha acabado, pues, por presentarse como absolutamente incontestable e inalienable algo que no es un derecho legalmente existente».
} 
este tridente uno de sus brazos, el respeto a la legalidad y a las decisiones judiciales ${ }^{13}$, como evidenció al respecto el Tribunal Constitucional ${ }^{14}$.

\section{La Declaración Unilateral de Independencia del Parlamento catalán y su eficacia en la creación de la República de Cataluña como Estado}

Cómo se ha señalado, el 10 de octubre de 2017, los auto-proclamados «legítimos representantes del pueblo de Cataluña» firmaron una Declaración Unilateral de Independencia, suspendida inmediatamente por ellos mismos, pero reactivada el 27 de octubre de 2017 con su aprobación por parte de la mayoría (70 votos) de los miembros del Parlamento de la Comunidad Autónoma de Cataluña presentes en el momento de la votación ( 82 de un total de 135 que conforman la Cámara) ${ }^{15}$. Con ella, pretendían constituir la república catalana, como Estado independiente y soberano.

Más allá de los hechos posteriores que dejaron sin efecto alguno dicha declaración por la intervención del Tribunal Constitucional y del Gobierno de España, la pregunta que debemos plantearnos es si una Declaración Unilateral de Independencia (DUI) ${ }^{16}$ - como la aprobada por el Parlamento catalán_ puede por sí misma conseguir el objetivo que se propone, que no es otro que dar lugar a la creación de un nuevo Estado. Una pregunta nada baladí si tenemos en cuenta que en el tenor de la citada DUI se afirma de manera expresa que, CONSTITUIMOS la República catalana, como Estado independiente y soberano, de derecho, democrático y social.

\footnotetext{
13 Esta obligación de respetar el Estado de Derecho, y en particular las obligaciones constitucionales también fue puesta de manifiesto por el Tribunal Supremo canadiense en su dictamen sobre el referéndum de Quebec.

14 En la Sentencia del Tribunal Constitucional de 8 de noviembre de 2017, citando la de 17 de octubre de 2017 , se dice, a este respecto, que la Cámara «se ha situado por completo al margen del derecho», ha dejado "de actuar en el ejercicio de sus funciones constitucionales y estatutarias propias y ha puesto en riesgo máximo, para todos los ciudadanos de Cataluńa, la vigencia y efectividad de cuantas garantías y derechos preservan para ellos tanto la Constitución como el mismo Estatuto». En fin, con tan grave atentado al Estado de derecho, ha conculcado, "con pareja intensidad, el principio democrático, habiendo desconocido el Parlamento que el sometimiento de todos a la Constitución es otra forma de sumisión a la voluntad popular, expresada esta vez como un poder constituyente del que es titular el pueblo español, no ninguna fracción del mismo», no pudiendo desvincularse en el Estado constitucional «el principio democrático de la primacía incondicional de la Constitución».

15 El texto de la DUI puede consultarse en el siguiente enlace: https://www.economiadigital.es/uploads/ s1/53/10/80/1/resolucion-parlament.pdf

16 A estos efectos, debemos llamar la atención sobre el hecho de que la expresión «Declaración Unilateral de Independencia» tiene una existencia relativamente corta. La misma fue acuńada, por vez primera, en relación con la declaración de independencia de Rhodesia del Sur del 11 de noviembre de 1965, realizada por una minoría blanca en clara vulneración de los principios fundamentales de protección de los derechos humanos y de libre determinación de los pueblos. Desde entonces, el término ha sido de uso recurrente para referirse a declaraciones de independencia realizadas en el marco de casos de secesión, siendo la de Cataluña la última de una larga lista.
} 
Para dar respuesta a este interrogante es necesario valorar las condiciones que impone el Derecho internacional en relación de la creación de un Estado y los distintos parámetros que entran en juego.

\subsection{El surgimiento de un Estado en el Derecho internacional: sobre sus elementos materiales y su confirmación a través de la efectividad}

Como es bien sabido, existe una práctica internacional asentada según la cual la existencia de un Estado en Derecho internacional viene condicionada por la confluencia de unos elementos materiales, a saber: territorio, población y organización del poder estatal ${ }^{17}$. Bien entendido que se requiere la existencia de los mismos en condiciones de independencia; esto es, que sea la propia entidad quien controle la totalidad del territorio sobre el que se asienta el aspirante a Estado, quien ejerza sus poderes soberanos sobre la población que habita en el mismo (tanto naciones como extranjeros), y quien despliegue de manera autónoma y sin ningún tipo de injerencia o control externo todas las competencias que lleva aparejado el poder estatal. Pues si tal actividad es desarrollada por un Estado tercero - como ocurre en Osetia del Sur, Abjasia, Transnistria o la República Turca del Norte de Chipre (RTNC)—, o por una organización internacional — caso de Kosovo-, la entidad carece de independencia $y$, en consecuencia, no se puede corroborar la confluencia de los requisitos materiales necesarios para su acceso a la estatalidad.

Pero, hay algo más. Tales precondiciones fácticas surgen esencialmente del principio de efectividad ${ }^{18}$, el cual hace referencia, como indica Pagliari (2014, p. 641), «a lo real y verdadero, en oposición a lo quimérico o dudoso; su significado tiene íntima vinculación con realidades, certezas, garantías, acciones, poder, en contraposición a lo aparente, iluso, o ineficaz».

La irrupción del principio de efectividad en el proceso de creación estatal, trae como consecuencia directa que no basta la mera declaración de independencia para ser un Estado, que dicha declaración no produce por sí misma ningún efecto jurídico. La exigencia de cumplir con el principio de efectividad hace que no exista automatismo en la creación objetiva del Estado, es decir, aunque se trate de un hecho, no es un hecho

\footnotetext{
17 Sobre este particular, resulta recurrente la referencia al artículo 1 de la Convención de Montevideo sobre derechos y deberes de los Estados de 1933 que dispone que el Estado como persona de Derecho Internacional debe reunir los siguientes requisitos: I. Población permanente; II. Territorio determinado; III. Gobierno; IV. Capacidad de entrar en relaciones con los demás Estados. Resultando, no obstante, que, si bien hay unanimidad estatal y doctrinal en relación con los tres primeros, no ocurre lo mismo con el cuarto, el cual podría ser considerado como una parte inherente del tercero y/o una consecuencia de la adquisición de la propia estatalidad.

18 El principio de efectividad permite al Derecho internacional establecer ciertas circunstancias en 'hechos-condiciones' y, de esta forma, atribuir consecuencias jurídicas a ciertas situaciones reales.
} 
instantáneo. Muy al contrario, se trata de un proceso. La necesaria efectividad -imperativa para que se cree un Estado en Derecho internacional— exige que esa declaración venga fortalecida y consolidada por el ejercicio de un control general y exclusivo — sin la batuta de otros- por parte del gobierno sobre la población y el territorio, de tal forma que sea capaz, no solo de establecer, sino sobre todo de mantener el orden interno, así como de participar en las relaciones internacionales de forma independiente. De esta forma, un mero acto de efectividad no es suficiente; se necesita, lo que podríamos denominar una 'efectividad duradera' que quede establecida de forma clara fuera de toda duda razonable. Es necesario, primeramente, un auténtico despliegue de todas las funciones propias del Estado, el cual debe desplegarse de manera continua y prolongada; $y$, por supuesto, que se trate de una autoridad realizada con total independencia.

Podríamos resumirlo, en palabras de Roth (2010, p. 7), de la siguiente manera: los criterios de Montevideo solo confieren derechos soberanos, obligaciones, poderes, inmunidad —esto es, personalidad jurídica—, a una comunidad política territorialmente coherente cuando se encuentra bajo el efectivo control de larga duración de un gobierno independiente.

Más aún, respecto de los casos de secesión, la práctica internacional establece, además, lo que se ha dado en denominar la 'teoría del éxito final'. Es decir, en estos supuestos no basta con el 'éxito inicial' de la secesión, sino que es necesario el 'éxito último' el cual solo se logra cuando el Estado 'padre o matriz' renuncia a todo intento de recuperación del territorio secesionado. Esto es, resulta necesario que acepte - de manera expresa o tácita - la situación fáctica generada; pues, en caso contrario, prima la presunción de integridad territorial del Estado 'padre'.

A la luz de lo expuesto es más que evidente que la DUI del Parlamento de Cataluńa por la que se proclama la república catalana no ha supuesto en ningún momento la creación de la misma como Estado. Tal podría haber sido, como mucho, el punto de inicio de un largo camino al acceso a la estatalidad. Un proceso que, a la vista de los datos que se conocen estaba y está lejos de poder llegar a ser una realidad. Aún no cuenta con las necesarias estructuras estatales (ejército, funcionarios propios, jueces, etc.); su solvencia económica —imprescindible para subsistir como Estadoes inexistente debido a su elevado endeudamiento ${ }^{19}$, lo que imposibilitaría el pago de sueldos a funcionarios, pensiones, proveedores, etc. Todo ello sin olvidar la posición

\footnotetext{
19 La deuda de Cataluńa se situó en 76.831 millones de euros en el tercer trimestre de 2017, acumulando ya unos 265000 millones, lo que representa, aproximadamente, ocho veces los ingresos en un ańo de la Generalitat por todos los conceptos (véase, entre otros, http://www.abc.es/espana/abci-deuda-oculta-plan-independentista-catalan265000-millones-euros-201709030329_noticia.html. Según un informe del propio Govern, necesitaría 30 años para sanear su deuda.
} 
y respuesta del Estado 'matriz' — España — en relación con el intento de secesión que hacen, hoy por hoy, imposible el 'éxito final' de la misma.

\subsection{Y la necesidad del respeto a la legalidad internacional como corolario del acceso a la estatalidad}

Pero el Derecho internacional actual no solo impone requisitos fácticos para acceder a la estatalidad, los cuales, hemos visto que no se cumplen en el caso de la 'pretendida república catalana'. La entrada en escena a partir de 1945 de unos principios fundamentales de este ordenamiento ha llevado a la inclusión de un criterio ańadido para poder acceder a la estatalidad, cual es el relativo al respeto a la legalidad internacional por parte de la entidad aspirante a Estado, en concreto, el debido respeto a esos principios fundamentales. Así se desprende de la práctica internacional en la materia, y de lo dispuesto en el artículo 6 de la Convención de Viena sobre sucesión de Estados en materia de tratados de $1978^{20}$.

En este sentido, en el proceso de acceso a la estatalidad deben respetarse indefectiblemente los siguientes principios:

- Prohibición del uso o amenaza de la fuerza (violado en el caso de la RTNC).

- Respeto de los derechos humanos (no respetado por los Bantustans en Sudáfrica).

- Libre determinación de los pueblos (violado en el caso de Rhodesia del Sur).

- No injerencia en los asuntos internos.

- Y, por supuesto, integridad territorial del Estado 'matriz', como han tenido oportunidad de señalar numerosos organismos internacionales. Es el caso del Consejo de Seguridad de Naciones Unidas respecto de la república de Sprska o de Somaliland; del Consejo de Europa, la UE y la OSCE en relación con Osetia del Sur, Abjasia, Chechenia, Transnistria; y de la OUA respecto de Katanga, Biafra y Anjouan. Todos estos principios juegan un papel fundamental en el ordenamiento jurídico internacional pues de ellos emanan normas imperativas. La consecuencia jurídica inmediata es que una DUI que viole alguno de esos principios y/o entre en contradicción con alguna norma de ius cogens se convierte automáticamente en un acto inválido e, incluso, nulo (principio 8 del Proyectos de artículos de la CDI sobre actos jurídicos unilaterales de 2006). Esto es, carente de efectos jurídicos; lo que implica que no produce el objetivo que persigue: la creación de un Estado.

\footnotetext{
20 Artículo 6: La presente Convención se aplicará únicamente a los efectos de una sucesión de Estados que se produzca de conformidad con el derecho internacional y, en particular, con los principios de derecho internacional incorporados en la Carta de las Naciones Unidas.
} 
Trasladada la exigencia del criterio de legalidad a la DUI del parlamento catalán, nos encontramos que la misma supone un claro incumplimiento del criterio de legalidad referido. Pues los autoproclamados representantes del pueblo catalán han vulnerado con su DUI el principio de integridad territorial del Estado español, el cual están obligados a respetar de conformidad con lo dispuesto en la Resolución 2625 (XXV), antes citada. Y tal es así, porque, como ya se ha seńalado, en caso de pueblos no coloniales el Derecho internacional solo reconoce la autodeterminación interna, no ostentando derecho alguno a la autodeterminación externa, la cual solo existe si está reconocida en el ámbito doméstico del Estado 'matriz', bien a priori por el propio derecho interno, bien ad hoc por el propio Estado. Condicionantes ambos que no se cumplen en el presente caso, pues ni el derecho español reconoce el derecho a la separación de las entidades territoriales que conforman el mismo, ni el Gobierno de España ha autorizado hasta la fecha tal separación ad hoc.

No obstante, hay quien podría objetar esta aserción sosteniendo que el parlamento catalán no está obligado a respetar el principio de integridad territorial pues, según lo afirmado por la CIJ en su Opinión consultiva sobre Kosovo, el alcance del mismo «se limita a la esfera de las relaciones interestatales» (CIJ, 2010, p. 403), como hemos señalado en otro apartado. A este respecto, resulta fundamental contextualizar debidamente esta afirmación de la CIJ para darle el significado y determinar el alcance que realmente tiene.

En esta línea, lo primero que debemos tener en cuenta es que la decisión de la Corte sobre este punto es adoptada tomando como base el artículo 2.4 de la Carta de Naciones Unidas que, en efecto, limita la prohibición del uso de la fuerza - contra la integridad territorial de los Estados- al ámbito de las relaciones interestatales; así como, en referencia al Acta de Helsinki, que se pronuncia en idéntico tenor. Sin embargo, la Corte ignoró el resto de instrumentos jurídicos que eran absolutamente pertinentes al caso y que llevarían a una conclusión manifiestamente diferente, particularmente las resoluciones del Consejo de Seguridad en la materia. Y tal es así, porque la aseveración realizada por la Corte forma parte de toda la arquitectura erigida por esta desde que 'modificó' el tenor de la pregunta que le hizo la Asamblea General, para hacer descansar la actuación relativa a la declaración unilateral de independencia, no en un pueblo o una autoridad representativa de un pueblo, sino en unos particulares que carecen de subjetividad en este ámbito; y así llegar a la predeterminada respuesta de su Dictamen ${ }^{21}$. De esta forma, si obviamos esa 'maniobra' de

\footnotetext{
21 Además, hay un factor cronológico que creo no debemos obviar cual es que, si bien las referencias a la obligación de respeto de la integridad territorial se dirigían primigeniamente a los Estados, también lo es que, en la fecha de adopción de los diferentes textos que las recogen, los Estados eran los únicos que podían poner en riesgo la integridad territorial de sus pares. Pero sucede que, en la actualidad, la persona humana y, fundamentalmente, los grupos
} 
la CIJ y nos situamos, como debemos, en el escenario de que una entidad secesionista lo que pretende, como bien afirman insistentemente, es ejercer su 'libre determinación', resulta evidente que no se trata de unos meros particulares, sino de un 'pueblo' que sí goza de subjetividad en este ámbito, y que sí está obligado al respeto de la integridad territorial del Estado donde radica —Resoluciones 1514 (XV) y 2625 (XXV) — El fundamento jurídico de esta obligatoriedad descansa en el hecho de que los entes a los que se les reconoce cierta subjetividad jurídica internacional pueblos, individuo... - están obligados a respetar los principios fundamentales de Derecho internacional y a ajustar su conducta a sus disposiciones, particularmente a aquellos de los que son destinatarios, como es el caso.

De esta forma, es evidente que 'los representantes del pueblo catalán' en su condición de tales, no solo se benefician, sino que están vinculados por el principio de libre determinación de los pueblos y, en consecuencia, por el respeto a la integridad territorial del Estado español, la cual se viola con su DUI, lo que la convierte en inválida y carente de efectos jurídicos.

Siendo esto así, no podemos sino poner de manifiesto, igualmente, la tergiversación y evidentes falsedades que se vierten en el Preámbulo de la DUI del parlamento catalán, al contener afirmaciones tales como que tienen «una autonomía limitada, que han convocado un referéndum para el ejercicio del derecho a la autodeterminación reconocido en el derecho internacional, que la constitución de la República catalana responde al impedimento por parte del Estado español de hacer efectivo el derecho a la autodeterminación de los pueblos», o, finalmente, que constituyen la república catalana «en el libre ejercicio del derecho de autodeterminación». El autogobierno del que disfruta la Comunidad Autónoma de Cataluña es el más elevado del mundo comparado con otras entidades territoriales dentro de un Estado soberano. Como se ha expuesto, el Derecho internacional no reconoce el derecho a un referéndum respecto de pueblos no coloniales ni a la independencia, tan solo la autodeterminación interna que está, pese a lo afirmado en el preámbulo, plenamente desarrollada y garantizada por el Estado español en relación con el pueblo catalán.

\footnotetext{
humanos — con distinta intensidad en materia de subjetividad internacional — pueden poner en riesgo la integridad territorial de los Estados. Prueba de esta circunstancia que indicamos es que la Declaración de las Naciones Unidas sobre los Derechos de los Pueblos Indígenas de 2007, ya extrapola específicamente la obligación de respeto de la integridad territorial de los Estados a los pueblos, grupos y personas.
} 


\subsection{El papel del reconocimiento individual y colectivo y la obligación de no reconocer a las entidades secesionistas}

Y un último apunte importante. La DUI del parlamento catalán incluye el siguiente llamamiento: «APELAMOS a los Estados y las organizaciones internacionales a reconocer la República catalana como Estado independiente y soberano». No es baladí, ni mucho menos, esa llamada al reconocimiento. Y tal es así porque como, ya advertía la Corte Suprema de Canadá en su dictamen a propósito de Quebec, el éxito final de una secesión dependerá de su reconocimiento por parte de la comunidad internacional (1998, p. 223).

Es por ello, que, habida cuenta el carácter descentralizado del Derecho internacional y, en consecuencia, la inexistencia de un mecanismo de verificación de la sanción o invalidez de una DUI, la misma debe proceder de la comunidad internacional Estados y organizaciones internacionales - en forma de no-reconocimiento como Estado a la entidad secesionista que pretender serlo a través de dicha declaración. Esta sanción que supone el no-reconocimiento es importante que se produzca, no solo como resultado de una decisión individual (el reconocimiento es un acto libre y discrecional), sino colectiva e institucional, lo que supone la ausencia total de reconocimiento. Y ello es así para que el no-reconocimiento no sea considerado como una decisión aislada de unos pocos — de la que pudiera cuestionarse su oportunidad y efectividad-, sino como el resultado de una decisión de la comunidad internacional en su conjunto.

Además, el no-reconocimiento institucional resulta fundamental en el aislamiento que se pretende con esta medida. Pues no ser admitido como Estado miembro de una organización internacional supone la parálisis internacional total. Todo lo cual supone la imposibilidad de actuar como Estado. Esto se hace particularmente evidente en el caso de los organismos especializados de la ONU, cuya pertenencia permite a los Estados contar con elementos tan básicos y esenciales como el prefijo telefónico, internet (UIT); código postal, envío de cartas, paquetes o giros postales (UPI); posibilidad de utilización del espacio aéreo extranjero (OACI); o el código ISO necesario, entre otras cosas, para el reconocimiento de pasaportes.

A este respecto, la práctica internacional demuestra que se ha gestado una norma consuetudinaria -iniciada con la crisis de Manchukuo y la Doctrina Stimsonsegún la cual no puede realizarse un acto de reconocimiento de una situación que haya surgido en violación de la legalidad internacional, según codifican los artículos 40 y 41 del Proyecto de artículos sobre responsabilidad internacional del Estado por hechos internacionalmente ilícitos de 2001. En consecuencia, ni los Estados ni las organizaciones internacionales pueden reconocer como Estado a entes cuya 
estatalidad haya sido adquirida en violación de los principios fundamentales del Derecho internacional anteriormente mencionados.

Este deber de no-reconocimiento de una entidad secesionista existe también por otra vía ${ }^{22}$ : el mismo está implícito en el principio de no injerencia en los asuntos internos del Estado 'matriz'. Dado que el Derecho internacional no regula el derecho $\mathrm{d}$ seceder, este se convierte en una cuestión puramente interna de cada Estado que puede reconocerlo o no. Si el derecho interno no reconoce ese derecho, ni el gobierno lo consiente, si un Estado preexistente reconoce como Estado a una entidad secesionista viola esta norma fundamental del derecho internacional ${ }^{23}$.

Establecida claramente la obligación de no reconocimiento ${ }^{24}$, no es de extrañar la contundente respuesta de la comunidad internacional a la DUI del Parlamento catalán. Tanto líderes europeos, como representantes de las instituciones de la UE afirmaron públicamente su no-reconocimiento como Estado a Cataluña y su absoluta defensa de la integridad de Espańa. La misma respuesta vino procedente de distintas partes del mundo: la Secretaría de Estado estadounidense, el presidente de México, el de Colombia o el de Chile, entre muchos. Lo cual deja sin esperanza alguna a la posibilidad de subsanar la ilegalidad de la DUI del parlamento catalán por el reconocimiento posterior de la Comunidad internacional.

\section{Conclusiones}

El intento secesionista de una parte de los representantes políticos catalanes, actuando en el seno de sus instituciones autonómicas, representa un importante test para el Derecho internacional, más relevante incluso que otros, como los casos de Quebec y Escocia, propiamente 'separatistas' al contar con el consentimiento de los Estados 'matrices'. Aunque el proyecto independentista catalán no se ha basado en una actua-

\footnotetext{
22 Además de naturaleza consuetudinaria, la obligación de no-reconocimiento puede tener naturaleza institucional. Tal sucede cuando se adopta una decisión de un órgano de una organización internacional instando a sus Estados miembros al no-reconocimiento como Estado del aspirante a serlo, lo cual es particularmente importante en el caso de una resolución del Consejo de Seguridad habida cuenta, tanto el carácter vinculante de la misma, como el hecho de que su obligatoriedad afecta nada menos que a sus 193 Estados miembros.

23 La Declaración sobre la inadmisibilidad de la intervención y la injerencia en los asuntos internos de los Estados, adoptada por la Asamblea General de Naciones Unidas en 1981 (Resolución 36/103), recoge claramente la prohibición del reconocimientos al incluir como contenido f): «el deber de todo Estado de abstenerse de promover, alentar o apoyar, directa o indirectamente y bajo cualquier pretexto, las actividades de rebelión o secesión dentro de otros Estados o cualquier acción encaminada a alterar la unidad o a socavar o subvertir el orden político de otros Estados». 24 La obligación de no-reconocimiento comporta un deber general de aislamiento de la entidad ilegal el cual se concreta, entre otras, en las siguientes obligaciones: no entablar relaciones convencionales; no establecer relaciones diplomáticas; rechazar su admisión y participación en organizaciones internacionales; no emprender relaciones económicas o comerciales; rechazar todo efecto jurídico a los actos constitucionales, legislativos o administrativos llevados a cabo por el régimen ilícito.
} 
ción extranjera, como Abjasia o la RTNC, ni en un conflicto armado interno, como Croacia o Eritrea, su apelación al Derecho internacional como fundamento de sus aspiraciones requiere un análisis riguroso del mismo.

En el estado actual del Derecho internacional, no hay un auténtico derecho de autodeterminación fuera de las situaciones de dominio colonial o por la fuerza. Pretender extender este derecho a las minorías nacionales es desconocer la génesis y la naturaleza de los Pactos de Nueva York de 1966 y la realidad de la práctica internacional posterior a la Resolución 2625 (XXV) de 1970 en la que se recoge la 'cláusula democrática'. No se puede afirmar con rotundidad que haya en la actualidad, casi cincuenta años después de la declaración de la Asamblea General de la ONU, una norma consuetudinaria internacional que reconozca el derecho a la 'secesión-remedio'. La práctica internacional no es uniforme ni general, sino muy escasa y contradictoria. No se puede interpretar ampliamente el principio de libre determinación de los pueblos, erosionando gravemente al mismo tiempo el principio de integridad territorial de los Estados, sin una práctica uniforme que exprese una auténtica convicción jurídica. Tampoco existe en el Derecho internacional ni un derecho a recuperar la estatalidad pérdida en tiempos históricos remotos ni un 'derecho a decidir' basado en un principio democrático sin respeto al Estado de Derecho y, por tanto, que obvie la legalidad vigente y el debido sometimiento a las decisiones judiciales.

La existencia de un Estado, su creación, requiere una efectividad duradera, es decir, el ejercicio real de la administración de su territorio y su población y la plena representatividad internacional sin sometimiento ni dependencia de ningún otro sujeto internacional. Por tanto, sin esa efectividad y sin ese 'éxito último' no tiene ninguna relevancia jurídico-internacional una declaración unilateral de independencia. Pero, además, un pueblo debe cumplir la legalidad internacional, como los Estados, las organizaciones internacionales y los individuos, y en este caso respetar el principio de integridad territorial del Estado en el que está integrado. Como los demás sujetos deben respetar dicha legalidad y dicho principio de integridad territorial y en consecuencia deben abstenerse de reconocer a una entidad proclamada como Estado en incumplimiento del ordenamiento jurídico internacional y, por lo dicho, también el interno de los Estados.

La Ley de Referéndum del Parlamento de Cataluña y la DUI emanada del mismo no solo no están basadas, por tanto, en el Derecho internacional, sino que lo vulneran manifiestamente y es, por ello, una enorme contradicción que se manifieste en el artículo 4.2 de la Ley de Transitoriedad que "Cataluña actúa respetando el derecho internacional» y en el 10.2 que «se siguen aplicando [...] el derecho internacional general y los tratados internacionales». 


\section{Referencias}

Anderson, G. (2016). A Post-Millennial Inquiry into the United Nations Law of SelfDetermination: A Right to Unilateral Non-Colonial Secession. Vanderbilt Journal of Transnational Law, 49(4), 1183-1254.

Bermejo García, R. y Gutiérrez Espada, C. (2008). La independencia de Kosovo a la luz del derecho de libre determinación. Documento de Trabajo 7. Real Instituto Elcano. Recuperado de http://biblioteca.ribei.org/1495/1/DT-7-2008.pdf

Buccheit, L.C. (1978). Secession. New Haven: Yale University Press.

Carrillo Salcedo, J.A. (2012). Sobre el pretendido 'derecho a decidir' en Derecho Internacional contemporáneo. El Cronista del Estado Social y Democrático de Derecho, 33, 20-22.

Cassese, A. (1995). Self-Determination of Peoples: A Legal Reppraisal. Nueva York: University Press Cambridge.

Christakis, Th. (1989). Le droit à l'autodétermination en dehors des situations de décolonisation. París: La Documentation Française.

Corte Suprema de Canadá. (1998). Renvoi relatif à la sécession du Quebec. Recuperado de http://scc-csc.lexum.com/scc-csc/scc-csc/fr/1643/1/document.do

Crawford, J. (2006). The Creation of States in International Law. 2a Ed. Oxford: Oxford University Press.

Eastwood, L.S. (1992). Secession: state practice and international law after the dissolution of the Soviet Union and Yugoslavia. Duke Journal Comparative \& International Law, 3, 299-350.

Gros Espiell, H. (1976). En torno al derecho a la libre determinación de los pueblos. Anuario de Derecho Internacional, 3, 49-74.

Guilhaudis, J.F. (1976). Le droit des peuples à disposer d'eux-mêmes. Grenoble: Presses Universitaires.

Hannum, H. (1993). Rethinking Self-Determination. Virginia Journal of International Law, 34, 1-69.

Higgins, R. (1994). Problems and Process: International Law and How We Use It, Oxford: Clarendon Press.

Humphrey, J.P. (1984). Human Rights and the United Nations. A Great Adventure. Nueva York: Transnational Pub.

CIJ - Corte Internacional de Justicia. (2010). Reports. Opinión consultiva sobre Kosovo de 22 de julio 2010.

Jarillo Aldeanueva, A. (2012). Pueblos y democracia en Derecho internacional, Valencia: Tirant Lo Blanch.

Martínez Jiménez, A. (2015). El derecho de autodeterminación de los pueblos en el siglo XXI. Pamplona: Aranzadi.

Musgrave, T. (2000). Self-Determination and National Minorities, Nueva York: Oxford University Press. 
Nanda, V. P. (1981). Self-Determination under International Law: Validity of Claims to Secede. Case Western Journal of International Law, 13, 257.

Pagliari, A.S. (2014). El principio de efectividad en el Derecho internacional público. En E. Rey Caro y C. Rodríguez (Dirs.), Estudios de Derecho Internacional en Homenaje a la Dra. Zlata Drnas de Clement (pp. 641-668). Córdoba (Argentina): Advocatus.

Palmisano, G. (1997). Nazioni Unite e autodeterminazione interna. Milán: Giuffrè.

Pons Rafols, X. (2015). Cataluña: Derecho a decidir y Derecho internacional. Madrid: Reus.

Remiro Brotóns, A. (2001). Desvertebración del Derecho internacional en la sociedad globalizada. Cursos Euromediterráneos Bancaja de Derecho Internacional, 5, 45-381.

Roth, B. (2010). Secession, Coups and the International Rule of Law: Assessing the Decline of the Effective Control Doctrine. Melbourne Journal of International Law, 11, 1-50.

Shaw, M.N. (1991). International Law, Cambridge University Press.

Soroeta Liceras, J. (2013). La opinión consultiva de la Corte Internacional de Justicia sobre Kosovo de 22 de julio de 2010. Revista Electrónica de Estudios Internacionales, 25. Recuperado de http://www.reei.org/index.php/revista/num25/articulos/ opinion-consultiva-corte-internacional-justicia-sobre-kosovo-22-julio-2010-unainterpretacion-judicial-sui-generis-para-caso-lo-es-aplicabilidad-clausula-salvaguardia-resolucion-2625-xxv-secesion-como-remedio

Tancredi, A. (2001). La secesione nel diritto internacionale. Padua: Cedam.

Tomuschat, C. (1998). Self-determination in a post-colonial world. En C. Tomuschat (Ed.), Modern Law of Self-determination (pp. 1-20). Dordrecht: M. Nijhoff.

Vidmar, J. (2015). The annexation of Crimea and the boundaries of the will of the people. German Law Journal, 16, 365-383.

Wilson, G. (2009). Self-determination, recognition and the problem of Kosovo. Netherlands InternationalLaw Review, 56(3), 455-481. https://doi.org/10.1017/S0165070X09004550

Fecha de recepción: 16 de marzo de 2018

Fecha de aprobación: 15 de junio de 2018 